\title{
Potential health risk assessment of urban soil on heavy metal content in Seri Kembangan
}

\begin{abstract}
Rapid urban development has made environmental quality of urban soil to decline. To have a an understanding of heavy metal pollution in urban soil, in this study, concentrations of $\mathrm{Pb}$, $\mathrm{Cr}$, and $\mathrm{Cd}$ in urban surface soil of Seri Kembangan, Selangor (Malaysia) were analysed and investigated. Potential health risk assessment from these heavy metals was also assessed. Results showed that surface soil of Seri Kembangan has been polluted by heavy metals. A total of 16 sampling locations were sampled representing three major areas namely residential, industrial and playground in Seri Kembangan. The results showed that $\mathrm{Pb}$ and $\mathrm{Cr}$ concentrations are the highest at playground area. While $\mathrm{Cd}$ concentration is the highest concentration in residential area. Heavy metal concentrations were subsequently used to establish potential health risk assessment (non cancer risk) using Hazard Index. The order of hazard index of heavy metal in urban soil of Seri Kembangan was $\mathrm{Pb}>\mathrm{Cd}>\mathrm{Cr}$. Hazard Quotient values exceeded 1 for $\mathrm{Pb}$ indicating potential non-cancer effect to human health via soil ingestion. Since health effects caused by $\mathrm{Pb}$ have long-term effects, especially on children, other pathways (inhalation and dermal) need to be considered. Other pathways are crucial to provide a bigger picture of potential health risk assessment of urban soil in Seri Kembangan.
\end{abstract}

Keyword: Urban soil; Heavy metal; Ingestion; Hazard quotient 